\title{
Development of Processing Stress Diacritics in Reading Greek
}

\author{
Athanassios Protopapas \\ Institute for Language \& Speech Processing, Greece \\ Svetlana Gerakaki \\ University of Athens
}

\begin{abstract}
In Greek orthography, stress position is marked with a diacritic. We investigated the developmental course of processing the stress diacritic in Grades 2 to 4 . Ninety children read 108 pseudowords presented without or with a diacritic either in the same or in a different position relative to the source word. Half of the pseudowords resembled the words they were derived from. Results showed that lexical sources of stress assignment were active in Grade 2 and remained stronger than the diacritic through Grade 4 . The effect of the diacritic increased more rapidly and approached the lexical effect with increasing grade. In a second experiment, 90 children read 54 words and 54 pseudowords. The pattern of results for words was similar to that for nonwords suggesting that findings regarding stress assignment using nonwords may generalize to word reading. Decoding of the diacritic does not appear to be the preferred option for developing readers.
\end{abstract}

The cognitive processes of reading have received substantial attention over the past decades. Researchers working primarily in English, but also in other languages as well, have begun to elucidate the mechanisms and representations involved in reading aloud printed words and, to some extent, in comprehending text. The main focus has been on a presumed transformation between the visual perception of (sequences of) letters (graphemes) and the phonological specification of (sequences of) segments (phonemes). The study of how graphemes are decoded into phonemes, and of how whole words in one's "sight vocabulary" are recog-

Correspondence should be sent to Athanassios Protopapas, Institute for Language \& Speech Processing, Artemidos 6 \& Epidavrou, GR-151 25 Maroussi, Greece. E-mail: protopap@ilsp.gr 
nized has largely occupied the research effort devoted to reading. Aspects of reading performance not directly involved in grapheme-to-phoneme conversion or word recognition have generally received less attention. Thus, comparatively little is known regarding suprasegmental aspects of reading, such as assigning stress or appropriate intonation (but see recent work in English by Arciuli \& Cupples, 2006; Monaghan, Arciuli, \& Seva, 2008; Ševa, Monaghan, \& Arciuli, 2009), as well as about orthographic information besides letters, such as diacritical marks and punctuation. In this article we address this lack of information by focusing our attention on stress assignment in reading, in particular on the processing of written diacritics for stress assignment and on the developmental course of this skill through the early grades. We report two experiments in which children were asked to read aloud pseudowords and words while the availability of lexical and orthographic information about stress assignment was controlled in varying stimulus and presentation conditions. The results of these experiments contribute to a richer picture of the development of reading skill and may help us understand more fully the demands and strategies involved in achieving expert, fluent reading.

\section{DIACRITICS IN READING}

A diacritic is defined as "a mark added to a character to indicate a modified pronunciation (or sometimes to distinguish homophonous words)" (Daniels \& Bright, 1996, p. xli), the term "character" referring here to "any self-contained element of a writing system" (p. xl), such as letters. In many European languages diacritics are used to modify the phonetic value of letters. For example, different high front vowels are denoted with accent diacritics on the letter $e$ in French; vowel fronting is denoted with umlaut in German; vowel length is denoted with accents in Hungarian (Csépe, 2006), Czech, and Slovak (Comrie, 1996); and consonant palatalization is denoted by the háček in several Slavic and Baltic languages (Comrie, 1996). In these cases, diacritics contribute to the overall visual shape of the letter they are combined with to determine the corresponding segmental value. In this sense, these combinations of letters with diacritics may appropriately be treated as separate letters (or graphemes) in a transparent system of mappings between graphemes and phonemes at the segmental level. Although letters with diacritics are often treated as separate letters for lexicographic purposes, they may be treated as variants of the same letter perceptually. For example, in Turkish, letters differing only in a diacritic caused as much repetition blindness as identical letters and more than distinct letters, consistent with a perceptual status as "variants" of the same letter (Ayçiçeği \& Harris, 2002).

Diacritics are also used for suprasegmental functions. In some tone language adaptations of the Roman alphabet, diacritics placed above or below the vowels denote phonemic tones, as in Vietnamese (Đình-Hoà, 1996) and the pīnyīn 
romanization system for Mandarin Chinese (Mair, 1996). In some European languages with lexical stress, including Greek, Spanish, and Italian, the acute accent mark is used to signify stress assignment at least in certain cases (e.g., when irregular or unpredictable). In these cases diacritics do not contribute to the segmental characterization of the phonological word but operate on a suprasegmental tier. There is some evidence, in Italian, for a processing advantage offered by the presence of the diacritic (Cubelli \& Beschin, 2005). Specifically, patients with severe neglect dyslexia were insensitive to the diacritic, whereas patients with a less severe form of neglect were more accurate in reading accented words than nonaccented words (but not nonwords). On the basis of these findings, Cubelli and Beschin concluded that the diacritic is "computed separately from letter identity and acts as an important cue for lexical access" (p. 325).

Data on processing of stress diacritics for lexical access in visual word recognition are scarce. In Spanish, Gutiérrez Palma (2003; Gutiérrez-Palma \& PalmaReyes, 2008) investigated the role of the stress mark ("la tilde") in a series of priming experiments. He argued that, if stress influences the process of lexical selection, and if the stress mark is processed to derive stress, then target stimuli preceded by a prime with stress mark congruent with their stress pattern should be recognized more rapidly than target stimuli preceded by a prime with an incongruent stress mark. A priming effect was found only for a stimulus-onset-asynchrony (SOA) of $143 \mathrm{msec}$, consistent with (a) processing of the diacritic to derive stress and (b) either late incorporation of stress in lexical representation or serial processing of the visual stimulus such that the stressed syllable (which is one of the last three) is encountered late in the process. On the other hand, a subsequent priming experiment using stress minimal pairs (i.e., segmentally identical words differing only in which syllable is stressed) as targets revealed effects of the stress diacritic at SOA of $33 \mathrm{~ms}$, consistent with previous findings (Domínguez \& Cuetos, 1998, 2002, as cited in Gutiérrez Palma, 2003, p. 123), suggesting that stress may be computed in very early stages of lexical processing.

A stress diacritic is also used in Greek. Studies have focused on the extent to which the diacritic is in fact processed during reading, as preliminary studies indicated that seventh-grade children make very few $(1.6 \%)$ stress assignment errors in words but many such errors (14.1\%) in nonwords, in which they apparently fail to fully process or take into account the printed diacritic (Protopapas, 2006). More recent studies, using nonwords presented with or without a diacritic, have confirmed that the diacritic is processed to derive stress information but that it is not sufficient to determine stress in every case without support from lexical activation (of word neighbors), both for seventh- to ninth-grade children (Protopapas, Gerakaki, \& Alexandri, 2006) and, to a lesser extent, for adults (Protopapas, Gerakaki, \& Alexandri, 2007).

In sum, diacritics are used in reading across a range of languages and for several linguistic purposes, encoding features ranging from segmental identity and pho- 
netic variants to suprasegmental information such as stress assignment. There is some evidence that diacritics are processed timely in the course of reading and that they contribute to reading performance. Little is known regarding how completely or systematically they are processed in each case and what determines the extent to which they are incorporated and integrated in the processing of written language. Practically nothing is known about the developmental course of this processing. Despite the ubiquitous presence of written marks ranging from punctuation and accents to segmental modifiers in many languages, it is not known when and how children begin to take into account these marks as they learn to read, whether they find that an easy or difficult task, and when and how they reach adult levels of competence in this respect relative to the development of their "mainstream" reading skills regarding fluent word recognition and reading with comprehension.

\section{STRESS ASSIGNMENT IN READING GREEK}

In stress-assigning languages it is necessary to take word stress into account when reading aloud to produce the words correctly. Fixed-stress languages, in which stress position is the same in every word, pose no special problem to the reader in that stress assignment does not depend on deriving any information from print or from the mental lexicon. In contrast, in free-stress languages the stressed syllable depends on the identity (or morphophonological shape) of the word. In other words, stress is a lexical property, at least to the extent not predictable from sublexical information (e.g., phonological constraints). In such languages, stress assignment must occur at the word level, at least for the nondefault or nonpredictable items. For the reader, this raises the question of when and where stress processing takes place.

Greek is a free-stress language with the constraint that stress must fall on one of the final three syllables of the word (Malikouti-Drachman \& Drachman, 1989; Petrounias, 2002; Revithiadou, 1999). The domain of stress is the "phonological word" (or, in the hierarchy of Nespor \& Vogel [1986], the clitic group), which typically includes a content word and any clitics that may attach to it. Phonological (Malikouti-Drachman, 2002) and developmental (Kappa, 2002) considerations suggest that a trochaic meter, that is, a penultimate-syllable stress pattern, may be dominant, or "default," in Greek, as it is also said to be in other languages such as Spanish (Gutiérrez Palma, 2003), Italian (Colombo, 1992), and Portuguese (Nunes, Roazzi, \& Buarque, 2003). Indeed, a relative majority of words are stressed on the penult (approximately $28 \%$ vs. $16 \%$ with antepenultimate and $19 \%$ with final stress, based on printed text corpora; Protopapas, 2006).

Stress position is indicated in the Greek orthography with a written diacritic similar to the acute accent. This diacritic is obligatory in every word with two or more syllables, thus providing the reader with a reliable cue to stress assignment. Omission of the 
diacritic is a spelling error. Use of the diacritic in reading and writing is explicitly taught to beginning readers in Grade 1 (Velalidis, Voujoukas, Kalapanidas, Kanakis, $\&$ Melas, 1994). However, studies have revealed that the mental lexicon and the diacritic both contribute stress assignment information during reading and, in addition, a "default" strategy of stressing the penultimate seems to be available to Greek readers.

Specifically, Protopapas et al. (2006) found that children in Grades 7 to 9 pronounced minimally changed nonwords presented without a diacritic with stress assigned consistent with the source word approximately $86 \%$ of the time (for high-frequency source words). Nonwords not resembling any words, presented with a diacritic, were pronounced with stress assignment consistent with the diacritic on average $82 \%$ of the time. The default metrical pattern emerged both in readings of items presented without a diacritic, as a relative preponderance of penultimate stress responses ( $62 \%$ for completely changed nonwords), and in readings of items presented with a diacritic, as a significant tendency for stress assignment errors towards the penultimate. In a follow-up study with adults, Protopapas et al. (2007) found approximately $84 \%$ readings of minimally changed items presented without a diacritic consistent with the source word, $91 \%$ readings of completely changed items consistent with the presented diacritic, and $62 \%$ readings of completely changed items presented without a diacritic with penultimate syllable stress. Thus, for both of these samples, all three potential sources of information (lexical, diacritic, default) were found to influence stress assignment in reading.

There were some important differences between the two studies. The children sample was drawn from the general middle-class school population whereas the adult sample comprised primarily graduate students. Children read aloud the list of pseudowords printed on a sheet of paper, under no time constraint, whereas adults read aloud the same items individually displayed for $1,500 \mathrm{msec}$ on a computer screen. Yet adult stress assignment was influenced more strongly by the diacritic than by the lexical resemblance, whereas for the children the opposite was true. The higher performance of adults in observing the diacritic for stress assignment suggests that the general school population, at least by seventh grade, has not yet fully automatized or integrated processing of the stress diacritic, whereas a select group of adults achieves very high performance in processing the diacritic even under time pressure.

\section{AIMS AND RATIONALE OF THE CURRENT STUDY}

In light of these findings it seems justified to wonder what happens in the early school years, if it takes more than 7 years of school to achieve a level of processing the diacritic that exceeds lexical influences. In the following we report two experiments designed to investigate the early stages of learning to process the diacritic. To ensure adequate reading performance, on which stress assignment could be ob- 
served, we tested children at the end of Grades 2, 3, and 4. Pilot testing indicated that many children in Grade 1 were unable to read fluently three-syllable nonwords. They could decode and correctly pronounce the stimuli on a segmental level but would often do so on a syllable-by-syllable basis, without any clear prominence, making it impossible to judge stress assignment. The three-syllable constraint on Greek stress assignment necessitated the use of stimuli with at least three syllables to properly counterbalance stress positions. Therefore only children from Grade 2 onward participated in the experiments.

The purpose of the experiments was multifold. We set out to investigate the course of development of the three sources of information (lexical, diacritic, and default) using nonwords controlling the relative availability of information from each source. More specifically, we were interested in the development of processing the diacritic, and in whether (or when) the influence of the diacritic on stress assignment is greater than that of lexical activation. We were also interested in relating changes in processing the diacritic to the overall development of reading skills which is expected to occur rapidly during these school years. Finally, to examine whether findings with nonwords and conclusions reached on the basis of those can be justifiably extended to word processing, we replicated and extended the stress assignment studies using the actual source words.

\section{EXPERIMENT 1}

In the first experiment we applied the method of Protopapas et al. (2007) to children in primary Grades 2, 3, and 4. We constructed two kinds of nonword stimuli based on specific source words: one resembling a particular word well known to the children, and another not resembling any particular words. This manipulation controls the availability of lexical information for stress assignment. If children can recognize the words that are similar to the nonword stimuli, and activate them in their mental lexicon-and if metrical (i.e., stress assignment) information is stored in the mental lexicon, and can be accessed when the words are activated-then the manipulation of word resemblance will reveal influences of the lexicon on stress assignment in reading.

The stimuli were presented with or without a diacritic, and the diacritic, when present, was either in the same position as in the source word or in a different position. This manipulation controls the availability of orthographic (diacritic) information for stress assignment. If children can process the diacritic for the purpose of assigning stress - and if they routinely process diacritics in the course of reading such that this skill is sufficiently practiced, hence efficient- then the presence of the diacritic will lead to stress assignment consistent with it. Positioning the diacritic to support, or oppose, the lexical information, will show which information source is dominant and how much it can be affected by the other source. Hence the 
diacritic manipulation will reveal influences of the diacritic on stress assignment in reading.

The effects of information sources for stress assignment were examined for developmental trends, primarily for linear changes across grades. In addition, a reading fluency test was administered to track overall reading development for the children, to serve as a reference and potential correlate of improvements in stress assignment across grades, and of potentially shifting importance between different sources of information.

\section{Method}

Participants. Ninety schoolchildren in total, attending Grades 2,3 , and $4,{ }^{1}$ in three private schools in and around Athens, participated in the experiment voluntarily, with the consent and permission of the school director and their teachers. There were 15 boys and 15 girls from each grade.

Materials. An initial list of three- and four-syllable words was based on Grade 2 "basic vocabulary" 2 to ensure that all children would be highly familiar with them in print. Each word was used to create two kinds of pseudowords (two "change" conditions, differing in word resemblance), by manipulating individual consonant graphemes along the three phonetic dimensions of voicing, manner, and place of articulation, and individual vowel graphemes along the two dimensions of height and place/rounding. A minimally changed nonword, highly resembling the source word, was made by segmental alteration of 1 to 3 phonetic features, most often by replacing a single consonant letter. A completely changed nonword, not resembling any particular word, was made by altering 2 to 11 phonetic features, replacing several letters while retaining the vowel/consonant distinctions and syllabic structure of the item. In a few cases single consonants were inserted or deleted. The 216 resulting items were all phonotactically acceptable.

The pseudowords were submitted to a pretest to ensure that the minimal change items activated the corresponding source words and that the complete change items did not activate any particular words. The pseudowords were printed on 3 sheets of 72 items each, and each sheet was given to 8 second-grade children and 8 third-grade children (none of which participated in the main experiment). The chil-

\footnotetext{
${ }^{1}$ In Greece, children enter first grade upon completing their 6th year of age. Therefore, the ages of Grade 2 children at the time of testing must be in the range of 7;8-8;7 (years;months). The corresponding range for Grade 3 is 8;8-9;7 and for Grade 4 9;8-10;7.

${ }^{2}$ The "basic vocabulary" is a fixed list of words included in the primary education language textbooks of the national curriculum (Ministry of Education, 1997). These words are encountered frequently in the schoolbooks and are used often for spelling and reading drills throughout the school years. Because of the limited experience of children in these grades with general reading materials, this list is a more reliable source of familiar (high-frequency) written words than printed text corpora.
} 
dren were asked to read each pseudoword and to write next to it a real word that came to mind. Minimally changed pseudowords were discarded if fewer than 11 children $(M=13.6, M d n=14$ children) produced the exact source word or if more than 2 children $(M=.7, M d n=.5$ children) produced a word stressed on a different syllable than the source word. Completely changed pseudowords were discarded if more than 2 children $(M=.2, M d n=0$ children) produced the same word (either the source word or any other word). ${ }^{3}$

The resulting set of 108 pseudowords included 54 minimally changed items and 54 completely changed items (available from the authors upon request). In each stimulus group there were 27 three-syllable and 27 four-syllable items, 9 for each stress position (antepenultimate, penultimate, and final-syllable stress). From these nonwords, stimuli were prepared in three "diacritic presentation" conditions: (a) without a stress diacritic, (b) with a diacritic at the same position as the corresponding source word, and (c) with a diacritic at a different position, counterbalanced across source-word stress positions. Three test sheets were prepared with 108 stimuli each, in equal proportions of word resemblance, length (number of syllables), presentation condition (existence and position of stress diacritic), and stress position of source word. Items were randomly assigned to each sheet, and randomly ordered in it, with the constraint that each item would appear on each sheet in exactly one presentation condition. In this way each child would respond to every item once and would contribute an equal number of data points to each condition.

In addition to the pseudowords, children were tested with a word reading fluency task from the KLIMA Learning Difficulties Scale (Protopapas \& Skaloumbakas, 2007), which includes 84 words, one to six syllables long, of a wide printed frequency range, presented in three columns on a single sheet, to be read aloud and timed.

Procedure. Children were tested individually at a quiet room in the school during school hours in May (end of school year). They were asked to read aloud the items on each sheet and were encouraged to proceed as quickly as possible without making mistakes. Sessions were recorded on tape and all tasks were timed using a stopwatch.

\footnotetext{
${ }^{3}$ These criteria are substantially more lax than the corresponding criteria employed previously with older (Grades 7-9) children (Protopapas et al., 2006) and adults (Protopapas et al., 2007), because very young children evidently produce much more loose associations and stricter criteria would be impractical. For example, approximately half of the children produced a word in response to each completely changed item, whereas almost none of the adults produced any words in the corresponding test of the earlier study. However, the relaxed criterion still serves the intended purpose of ensuring that no particular words are consistently activated by the completely changed nonwords, whereas source words are consistently activated by the minimally changed nonwords.
} 
Analyses. We were primarily interested in measures of the relative influence of lexical, orthographic (diacritic), and default-pattern information on stress assignment, regardless of stress position. Because effects depend on the relation between the information provided by each source and the syllable actually stressed by the participants, it was necessary to construct informative indices of influence properly taking into account these relations while averaging across stress positions accordingly. To this end we followed previous work (Protopapas et al., 2006, 2007) in defining a Lexical index (LexI), a Penultimate index (PenI), and a Diacritical Index (DiaI), as follows:

- LexI was defined as the proportion of item readings consistent with the stress pattern of the corresponding original word (whether or not it was recognizable in the actual stimulus) minus the average proportion of item readings with different stress patterns. Thus, if an item were always stressed according to the stress pattern of the original word, LexI would be 1.00, indicating a perfect lexical effect. If an item were never stressed like the original word its LexI would be -1.00 . Finally, if an item were stressed equally frequently in each of the three possible positions, LexI would be 0.00 , indicating a lack of preference for the lexical stress pattern. For stimuli resembling their source words, LexI corresponds to the strength of the lexical information source for stress assignment. LexI represents lexical influence most clearly for stimuli presented without a printed diacritic.

- PenI was defined as the proportion of item readings with stress on the penultimate syllable minus the average proportion of item readings with stress on the final and on the antepenultimate syllable. PenI corresponds to the strength of the default pattern in determining stress assignment. It can be interpreted most clearly for stimuli not resembling any words presented without a diacritic, because in this case there is no competing information for stress assignment.

- DiaI was defined as the proportion of item readings consistent with the printed stress diacritic minus the average proportion of item readings with different stress patterns. DiaI is defined only for stimuli presented with a diacritic and coincides with LexI for stimuli presented with the diacritic in the same position as the original word. Dial corresponds to the strength of the orthographic (diacritic) information source for stress assignment most clearly for stimuli not resembling any particular words.

Calculation of these indices effectively removes biases in estimating the effects of the corresponding information sources, because of fully counterbalanced materials and averaging across all possible stress positions.

Analyses of variance were performed both with participants as random factor, averaging across items (subjects analysis, denoted $F_{1}$ ), and with items as random 
factor, averaging across participants (items analysis, denoted $F_{2}$ ). Differences are reported as statistically significant when both tests reached the customary threshold of $\alpha=.05$.

\section{Results}

Reading performance. Table 1 lists general reading performance metrics derived from the experimental pseudoword list and the fluency assessment word list, separately for each grade. As expected, performance improved markedly at higher grades, with both segmental and stress errors in words dropping to less than $4 \%$ by the end of Grade 4 . In pseudowords there is little evidence of ceiling performance for the experimental items in the context of rapid improvement. In analyses of variance for fluency and segmental errors in both words and pseudowords, with grade and sex as fixed factors, a significant effect of grade was found in each case: word fluency, $F(2,84)=32.57, p<.0005$; pseudoword fluency, $F(2,84)=11.61$, $p<.0005$; word segmental errors, $F(2,84)=16.77, p<.0005$; pseudoword segmental errors, $F(2,84)=3.63, p=.031$, and no main effect of sex $($ all $F<1)$. The effect of grade was strongly linear in each of these four measures (for all linear contrasts, $p<.01$; for all quadratic contrasts $p>.3$ ).

Table 2 shows the results of linear regression analyses with grade as an independent variable accounting for differences in these four reading measures. Evi-

\section{TABLE 1}

Reading Performance of the Children in Experiment 1, Including Means Per Grade and Corresponding Standard Deviations (in Parentheses)

\begin{tabular}{lrrrrrrr}
\hline & \multicolumn{2}{c}{ Grade 2 } & \multicolumn{2}{c}{ Grade 3 } & & \multicolumn{2}{c}{ Grade 4 } \\
\hline Word list & & & & & & & \\
$\quad$ Read time (s) & 185.6 & $(45.0)$ & 137.3 & $(47.8)$ & 104.1 & $(24.6)$ \\
$\quad$ Stress errors & 13.2 & $(6.2)$ & 7.2 & $(5.4)$ & 2.8 & $(3.0)$ \\
Segmental errors & 10.9 & $(7.5)$ & 6.7 & $(6.0)$ & 2.3 & $(2.0)$ \\
Items correct (\%) & 91.0 & $(5.8)$ & 94.2 & $(4.4)$ & 97.8 & $(1.7)$ \\
Fluency (wpm) & 26.3 & $(7.3)$ & 38.8 & $(13.8)$ & 49.9 & $(11.5)$ \\
Pseudoword list & & & & & & & \\
$\quad$ Read time (s) & 336.4 & $(69.6)$ & 281.7 & $(87.2)$ & 250.7 & $(55.1)$ \\
Segmental errors & 23.3 & $(13.0)$ & 19.7 & $(11.8)$ & 15.3 & $(9.6)$ \\
Items correct (\%) & 83.1 & $(8.5)$ & 86.1 & $(7.2)$ & 89.1 & $(6.7)$ \\
Fluency (ppm) & 16.8 & $(4.8)$ & 21.7 & $(7.1)$ & 24.1 & $(5.4)$ \\
\hline
\end{tabular}

Note. The absolute number of segmental errors is reported separately from the number of correct items because it is possible to make more than one segmental error per item. The total number of items was 84 for the word list and 108 for the pseudoword list. Fluency was calculated individually as correct items per minute (words per minute [wpm] or pseudowords per minute [ppm]). Absolute accuracy and fluency measures are not directly comparable between words and pseudowords because the two sets were not matched in phonological complexity or length. 
TABLE 2

Results of Linear Regression Analyses of the Effect of Grade on Reading Performance Measures

\begin{tabular}{lccrcrr}
\hline Dependent Variable & $R^{2}$ & $B$ & \multicolumn{1}{c}{$t$} & \multicolumn{2}{c}{$95 \%$ CI } \\
\hline Word segmental errors & 0.29 & -4.30 & -5.92 & 0.000 & -5.74 & -2.86 \\
Word fluency & 0.43 & 11.80 & 8.19 & 0.000 & 8.94 & 14.66 \\
Pseudoword segmental errors & 0.08 & -4.03 & -2.72 & 0.008 & -6.98 & -1.09 \\
Pseudoword fluency & 0.21 & 3.61 & 4.78 & 0.000 & 2.11 & 5.11 \\
\hline
\end{tabular}

Note. The indicated lower and upper bound of the $95 \%$ confidence interval refers to the displayed unstandardized regression coefficient $(B)$. The independent variable was grade. Fluency was calculated individually as correct items (words, pseudowords) per minute. $\mathrm{CI}=$ confidence interval.

dently, word reading fluency is the measure most substantially and consistently improving at higher grades. The estimated yearly rate of improvement is more than 11 words per minute, that is, 20 to $30 \%$ per grade (depending on which grade is considered baseline for the calculation) or about $13 \%$ of the total word list. The corresponding yearly increase for pseudowords is less than four items per minute, approximately 17 to $23 \%$ per grade, or about $3.5 \%$ of the pseudoword list. The 95\% confidence intervals for the two fluency measures are widely separated and, because the length of the pseudoword list is greater than the length of the word list, it may be argued that the observed lower rate of improvement for pseudowords than for words indicates that the primary gain consistently achieved as children progress through grades is not of fluent decoding but of efficient sight word reading.

Stress assignment. Table 3 shows the LexI, PenI, and DiaI derived from the stress assignment counts. None of the indices approached 1.00, even in Grade 4, suggesting that stress assignment in nonword reading remains imperfect at these ages. The highest index value of .90 was observed in Grade 4 when lexical and diacritic information were consistent (minimally changed items, same as word diacritic presentation condition), and this value was well below 1.00 and statistically different from it. As expected, LexI was not statistically different from 0.00 in the absence of stress assignment information, that is, in completely changed nonwords presented without a diacritic. Moreover, DiaI for minimally changed nonwords presented with a diacritic on a different position was not statistically greater than zero, therefore the presence of the diacritic did not determine stress assignment in the presence of contradictory lexical information.

In comparison of LexI for minimally changed items between presentation without a diacritic and presentation with a diacritic at a different position, we found a statistically significant difference, $F_{1}(1,87)=91.06, p<.0005 ; F_{2}(1,53)=$ $159.16, p<.0005$, and a significant interaction with grade, $F_{1}(2,87)=10.28, p<$ $.0005 ; F_{2}(2,106)=22.30, p<.0005$, indicating that the difference increased sig- 


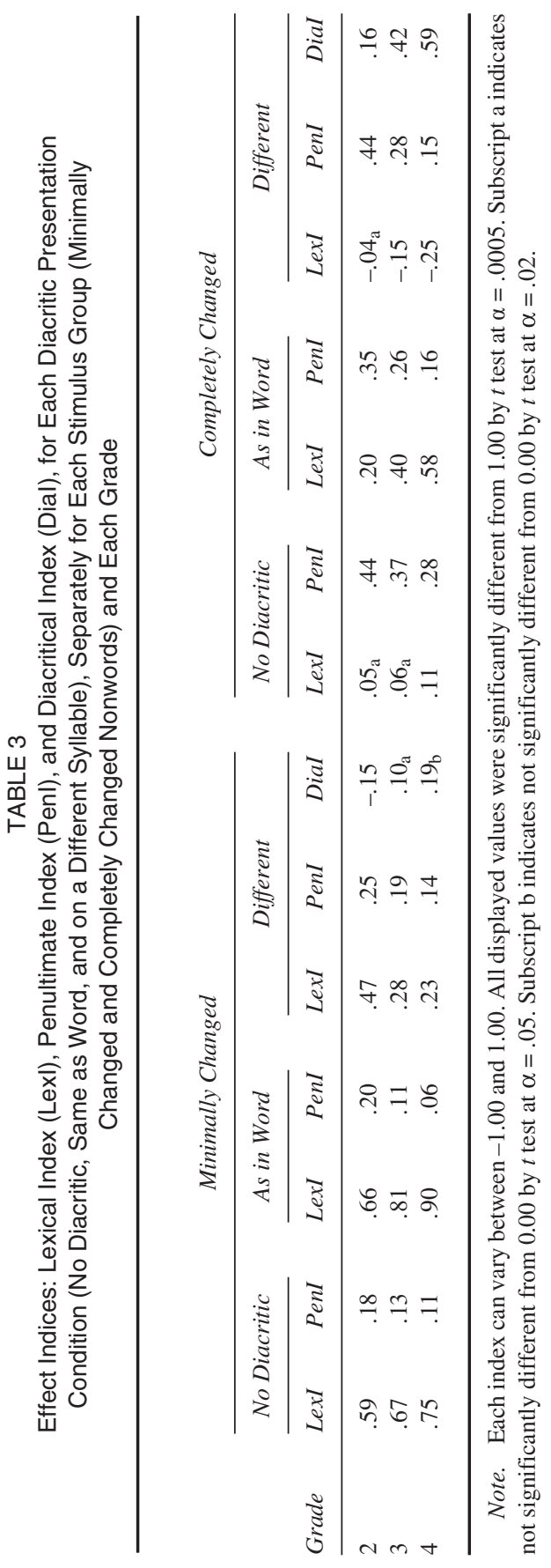


nificantly at higher grades. Therefore, the diacritic does exert an influence on stress assignment, which is not sufficient to completely overcome the lexical source but is gradually increasing. Comparison of LexI for minimally changed items between the no diacritic condition and the same as word condition revealed a statistically significant difference, $F_{1}(1,87)=48.45, p<.0005 ; F_{2}(1,53)=30.73$, $p<.0005$, indicating that the presence of the diacritic affected stress assignment also when it was consistent with the lexical information. The difference between these conditions did not interact significantly with grade, $F_{1}(2,87)=2.11, p=$ $.128 ; F_{2}(2,106)=1.11, p=.334$, indicating that the amount gained by the diacritic remained roughly constant across grades. One way to interpret this constancy is that as both the lexical and diacritic influences strengthen at higher grades, the diacritic achieves greater potential to affect stress assignment but there is increasingly less to be gained as the lexical source becomes stronger as well.

The difference in Dial between minimally changed items and completely changed items, presented with a diacritic in a different position, was statistically significant, $F_{1}(1,87)=166.44, p<.0005 ; F_{2}(2,212)=83.47, p<.0005$, indicating that lexical information partially (but not completely) overrides the diacritic when it is inconsistent with it. This difference did not interact significantly with grade, $F_{1}(2,87)=1.49, p=.232 ; F_{2}(2,212)=1.69, p=.188$, indicating that the impact of lexical information on the processing of the diacritic did not change appreciably within the range of grades examined. Comparison of LexI for minimally changed items with LexI for completely changed items, both at same as word diacritic presentation condition, revealed a statistically significant difference, $F_{1}(1,87)=$ $242.49, p<.0005 ; F_{2}(2,212)=53.92, p<.0005$, indicating that the availability of lexical information affected stress assignment also when it was consistent with the diacritic. The difference between these conditions did not quite interact significantly with grade, $F_{1}(2,87)=2.69, p=.073 ; F_{2}(2,212)=3.03, p=.050$, indicating that the additional information gained by the lexical source remains about the same in all three grades tested.

PenI was statistically greater than 0.00 in every stimulus and presentation condition, consistent with the presumed existence of such a default. In the condition where no other stress assignment information was available, that is, for completely changed items presented without a diacritic, PenI reached .44 in Grade 2, which was significantly greater than the corresponding estimate of the diacritic influence (DiaI $=.16$, for completely changed items presented with a diacritic in a different position) in the same grade, $F_{1}(1,29)=32.96, p<.0005 ; F_{2}(1,53)=13.36, p=$ .001 . However, this was only true for Grade 2: With grade as a factor in analysis of variance for completely changed items only, PenI for items presented without a diacritic was overall no different from DiaI for items presented with a diacritic, $F_{1}(1$, $87)<1 ; F_{2}(1,53)<1$. This effect interacted significantly with grade, $F_{1}(2,87)=$ $17.42, p<.0005 ; F_{2}(2,106)=42.31 p<.0005$, as the sign of the difference changes across grades such that DiaI becomes significantly greater than PenI in 
these conditions at Grade $4, F_{1}(1,29)=19.03, p<.0005 ; F_{2}(1,53)=22.29$, $p<.0005$.

The corresponding comparison between the strength of the default metrical pattern and the lexical source can be examined by comparing PenI for completely changed items presented without a diacritic against LexI for minimally changed items presented without a diacritic. With grade as a factor, the difference between these indices was statistically significant, $F_{1}(1,87)=99.10, p<.0005 ; F_{2}(1,106)$ $=33.16 p<.0005$, with LexI always greater than PenI. The interaction with grade was also statistically significant, $F_{1}(2,87)=9.17, p<.0005 ; F_{2}(2,212)=13.09 p$ $<.0005$, reflecting the fact that the difference became greater at higher grades. The difference was already statistically significant at its lowest value, in Grade $2, F_{1}(1$, $29)=7.89, p=.009 ; F_{2}(1,106)=5.10, p=.026$. Thus the presumed effect of the default metrical pattern remained below our low estimate of the influence of the lexical source throughout these three grades.

Developmental trends. A set of polynomial contrasts over grade were tested, separately for each stimulus type and diacritic presentation condition, to determine whether linear analysis would constitute an appropriate index of developmental trends. Statistically significant linear trends were observed in the great majority of cases (both in subjects and items analyses). Critically, there were no statistically significant quadratic trends, permitting further analysis via linear regression.

Table 4 shows the results of linear regression with grade as an independent variable, separately for each effect index as a dependent variable. The influence of the lexical information source for stress assignment grew significantly at higher grades, as seen by the statistically significant $B$ coefficient (.079) of LexI for minimally changed items presented without a diacritic. The influence of the diacritic also grew significantly, as seen in DiaI for completely changed items presented with a diacritic in a different position $(B=.219)$. The $95 \%$ confidence interval for the former (high bound of .122) did not overlap with the corresponding interval for the latter (low bound of .143). Thus it seems that the rate of growth of the influence of the diacritic over the grades significantly exceeded the rate of growth of the lexical influence on stress assignment.

The developmental course of the default patterns appears to be one of diminishing influence. All the slope estimates for PenI were negative and the one most clearly reflecting the default pattern alone (completely changed items presented without a diacritic) was statistically significant, its confidence interval not straddling zero. Thus during these early years of attaining reading skill, reliance on a default metrical pattern for stress assignment appears to recede somewhat.

Relation to reading skill. To determine whether stress assignment skills are related to the development of decoding or of sight-word reading we examined the correlations between the list-level reading measures and the stress assignment 


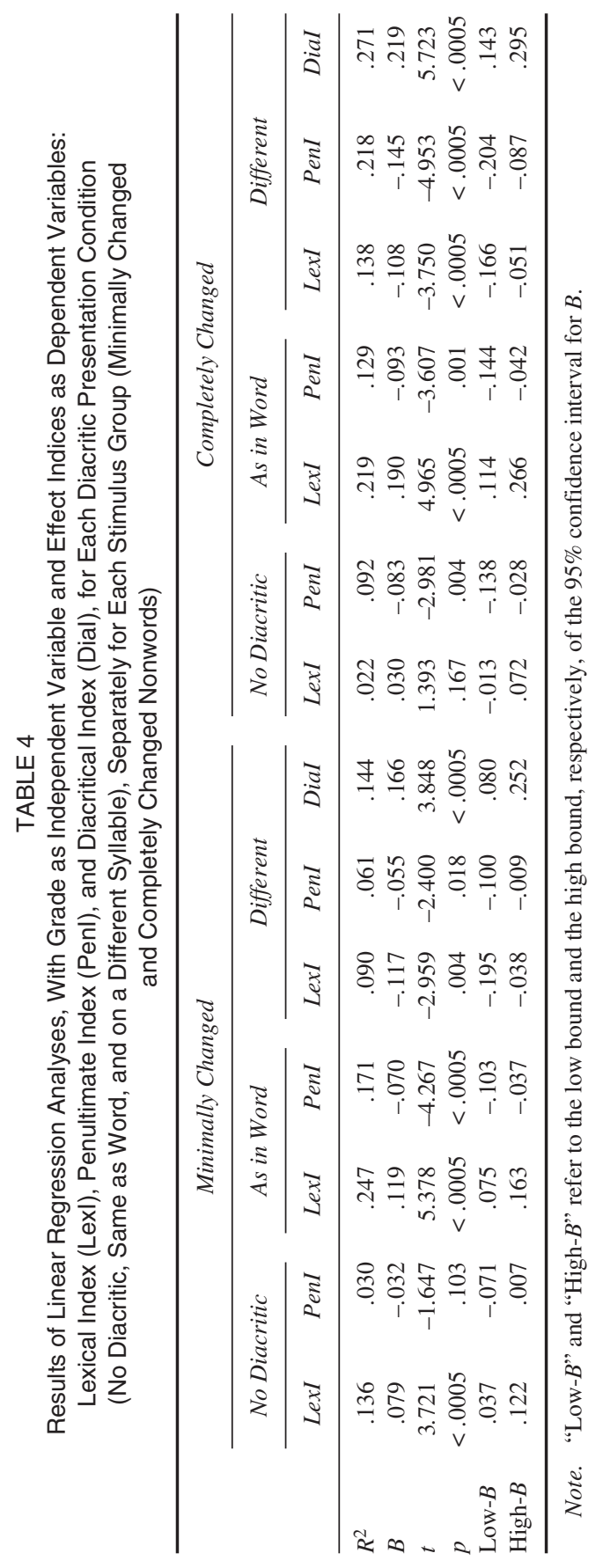


effect indices. Because grade alone accounts for large proportions of variance in word fluency and in certain effect indices, we partial out the effects of grade. If sight-word reading development is related to improvement in processing of the diacritic, then DiaI correlations should be greatest with word fluency, in which lexical knowledge presumably predominates. If, on the other hand, improvement in decoding skills is responsible for more adequate processing of the diacritic, then the correlation between word fluency and DiaI should diminish once grade is controlled for, and a stronger correlation should emerge between DiaI and nonword accuracy or fluency, for which decoding skills are critical.

Table 5 shows the partial correlation coefficients between the reading performance measures and the stress assignment effect indices, controlling for grade. The number of stress errors in word reading was the list-level measure most strongly related to stress assignment indices, including indices of lexical influence alone (-.45), diacritic alone (-.62 and -.57), as well as lexical and diacritic combined (-.72), for which the largest correlation coefficient of all was observed. This suggests that stress assignment in pseudowords is a good index of general stress assignment skill in regular word reading, and not some unjustified experimental manipulation of no ecological validity.

The correlations of the critical effect indices with word fluency (and accuracy) were larger than their correlations with nonword fluency (and accuracy), consistent with a view of stress assignment hinging on sight-word reading development and not with improved or more efficient decoding. Thus processing of the diacritic must be examined not as a special case of decoding but as part of the course of automatizing word recognition.

\section{Discussion}

These results unequivocally show that all three previously hypothesized sources of stress assignment information are active by the end of Grade 2. Developmental trends showed increasing effectiveness of both the lexical and the diacritic source of information across grades. The rate of increase of the influence of the diacritic was higher than the corresponding rate for the lexical source. It seems clear that the diacritic is processed increasingly more efficiently and affects stress assignment more in higher grades. The difference between lexical and diacritic influence was found to diminish across grades. Nevertheless, lexical influence remained substantially stronger than the diacritic throughout these school years.

Children read most nonwords accurately at the segmental level, that is, they did not confuse them with words. Therefore it is difficult to argue that the advantage of the lexical source for stress assignment is due to lexical activation overriding a perfectly complete and adequate processing of the diacritic available via decoding. The nonword neighbors used as "minimally changed" stimuli presumably acti- 


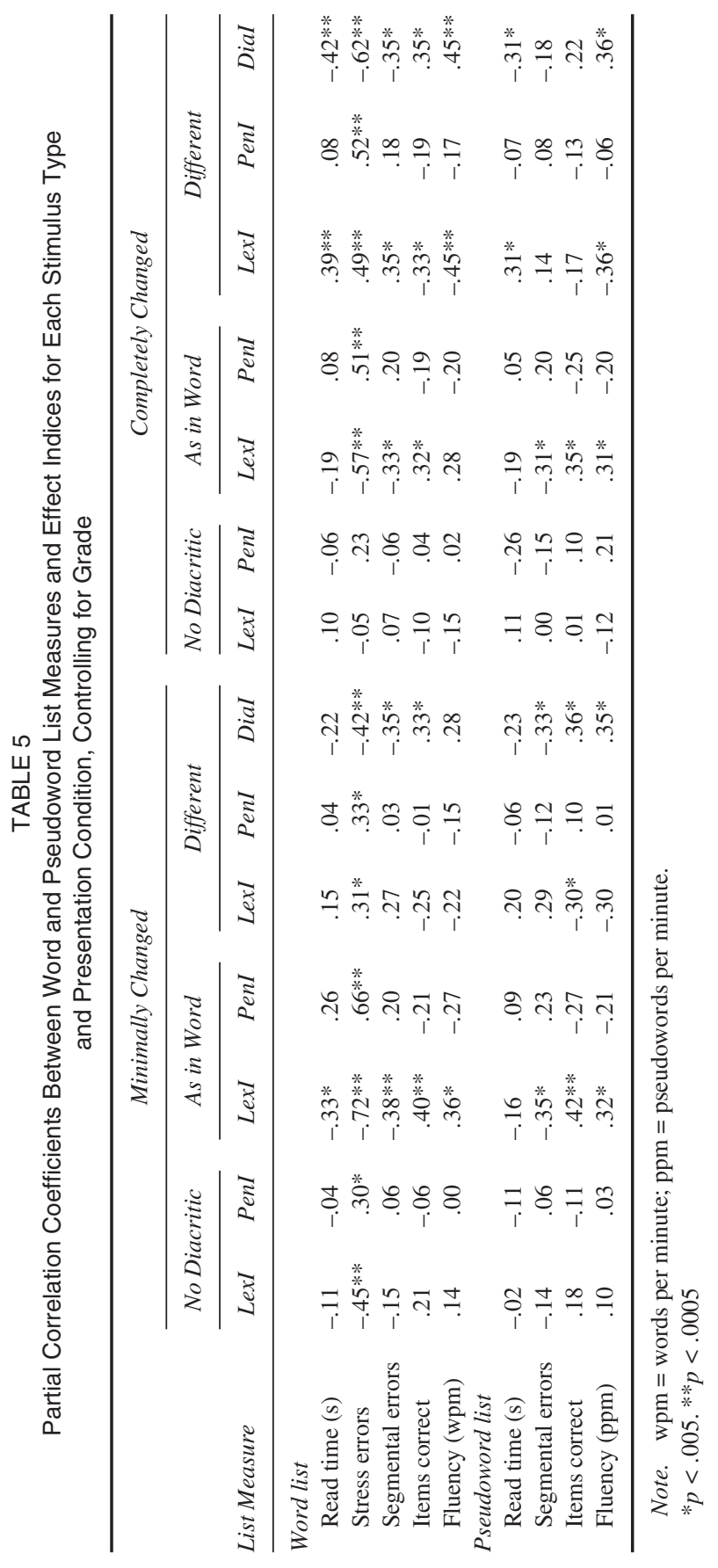


vated the intended words, but the activated lexical entries must have subsequently received strong inhibition, due to the mismatch, in order for the nonwords to be read correctly. Yet this presumed suppression evidently failed to suppress the metrical pattern associated with the words, which remained strong enough to preferentially determine stress assignment, especially in the lower grades.

In the past study with adult readers, the diacritic was found to be almost perfectly processed (Protopapas et al., 2007). Thus the processing of the diacritic seems to develop through secondary education until ceiling performance is reached, at least for a proportion of the population. Presumably, word recognition has already reached its maximum efficiency for those readers much earlier. We may therefore speculate that processing of the diacritic lags behind word recognition at the segmental level and can only eventually "catch up" after word recognition has reached a plateau. If this longitudinal development of processing the diacritic is dependent on the same kind of reading practice that accounts for other improvements in reading skill, it remains to be determined what kind of improvement it amounts to and precisely how it is affected by the developing reading skills.

Two obvious options for the processing of the diacritic are parallels to segmental reading skills: Children may learn to decode the diacritic into a metrical pattern, albeit more slowly than learning to decode graphemes into phonemes, or they may learn to incorporate the diacritic in the visual image of the words they increasingly recognize as belonging to their sight-word vocabulary. Stress sensitivity, an important prerequisite for fluent reading (Gutiérrez-Palma \& Palma-Reyes, 2007; Wood, 2006), presumably indexing facility with stress assignment, is already developed by the age of the children tested here. If the children have all that it takes to decode the diacritic, then the question arises why they learn to do it so much more slowly than learning to decode phonemes.

One possibility is that decoding the diacritic into a metrical pattern is much more difficult than decoding a grapheme into a phoneme. This is plausible because the relation of the diacritic to the representation of stress is more complex than the relatively straightforward conversion of a visual letter code into a phonological representation. To "decode" the diacritic, one needs to visually process it and note on which vowel it appears; then, after segmental specification is complete, and syllabified, to associate the syllable of the "tagged" vowel with a marked stress level. Decoding of the diacritic seems impossible without at least a cursory representation of the syllabic constituency of the word. Therefore, if one were to decode the diacritic, this process would necessarily have to occur late in the course of word recognition. Alternatively, some information would have to be held over while the segmental sequence is computed to be integrated with it at the syllabic level during the final stages of decoding, all the while occupying cognitive resources for the maintenance of the position of the diacritic and its association with a particular vowel. 
This explanation is consistent with findings from eye movement studies and the conclusion of Ashby and Clifton (2005) that stress assignment may be a final step of phonological assembly, similar to the conclusion of Gutiérrez-Palma and Palma-Reyes (2008) that stress assignment is a slow process. It is also consistent with a possible alternative hypothesis offered here according to which processing of the diacritic is efficient and typically completed rapidly and accurately but fails to affect reading because stress assignment information from the activated lexical entry has a chance to be accessed and incorporated earlier, either in the course of segmental assembly or by virtue of sight word recognition. That is, if decoding of the diacritic has to wait until the segmental specification is complete, then it might turn out to be irrelevant if during segmental specification the metrical pattern has already had a chance to be specified on the basis of the lexical information that becomes available in the meantime. Regardless of whether word phonology is assembled or addressed, on this view, decoding of the diacritic would be of marginal use to the extent that lexical representations become activated and automatically provide access to stress assignment information.

Alternatively, the diacritic might not be decoded into a metrical pattern but might be part of a holistic word representation in the sight-word vocabulary. If the diacritic operated in this way then we would expect little effect of its absence, as there would be no mismatch with the stored orthographic representation, but there might be a substantial effect of its misplacement, due to the mismatch. Such effects are difficult to observe in this experiment because the design did not allow precise timing of naming latencies, therefore we consider this in the next experiment. However, if the diacritic is gradually incorporated into a sight-word reading strategy as opposed to a decoding strategy, we should also observe (a) a general dominance of sight-word reading, and (b) a concordance between the attainment of sight-word reading skills and processing of the diacritic.

Evidence for reliance on sight-word reading, as early as Grade 2, may be sought in the pattern of stress assignment effects, particularly in effects of lexical activation. Nonword stress assignment consistent with similar words is strongly indicative of word activation, which is consistent with word recognition rather than with phonological assembly. Converging evidence from Italian, another orthographically transparent language, indicates that sight-word reading is the predominant reading strategy despite the viability of graphophonemic decoding and that children become fluent word recognizers (Barca, Burani, Di Filippo, \& Zoccolotti, 2006; Marcolini, Burani, \& Colombo, 2009; Pagliuca, Arduino, Barca, \& Burani, 2008; Zoccolotti et al., 2005).

In the present experiment, the development of processing the diacritic seems to follow the development of word fluency, an index of sight-word vocabulary, rather than pseudoword fluency, an index of decoding efficiency. Not only was DiaI for completely changed nonwords the fastest changing effect index (Table 4) across grades, consistent with word fluency being the fastest growing reading skill 
measure (Table 1), but also the partial correlation among these two measures, controlling for differences in grade, was the highest among all correlations between a stress assignment effect index and a word or nonword accuracy or fluency measure (Table 5). Although correlation does not imply causation, and the apparent common fate of these measures may be due to some other factor, these findings are consistent with the interpretation that processing of the diacritic is part of the development of sight-word reading fluency and not of improved decoding.

Nevertheless, despite the strong correlations between word stress assignment and the effects of various information sources on nonword stress assignment, it remains possible that nonwords are particularly difficult or problematic for developing readers, or that they are processed in a way sufficiently different from regular words that the aforementioned conclusions about the relative strength of various information sources and their developmental course may not validly generalize to word reading. To counter this potential criticism, in Experiment 2 we examined the same effect indices and their changes across grades using word stimuli.

\section{EXPERIMENT 2}

In this experiment we used real words along with nonwords to test whether the same pattern of results is obtained. If processing of word and nonword stimuli for stress assignment in reading is similar, then the only difference from Experiment 1 should be in the strength of lexical influences, which should be much greater here because lexical representations will match perfectly the word stimuli. Because we anticipated ceiling effects in word reading (and associated stress assignment) we used a timed procedure to increase the sensitivity of the method to detect small effects that may be caused by the lack (or incongruence) of the diacritic.

\section{Method}

Participants. Ninety schoolchildren in total, attending Grades 2,3 , and 4, in a private school in Athens, participated in the experiment voluntarily, with the consent and permission of the school director and their teachers. There were 15 boys and 15 girls from each grade. None of these children had participated in Experiment 1 .

Materials. Materials and presentation conditions were identical to those of Experiment 1, with one exception: Instead of the minimal-change nonwords, the original source words were used, replacing the corresponding minimal-change nonwords in the three experimental lists. 
Procedure. Children were tested individually in a quiet room in the school during school hours in March. Items were presented individually on a laptop computer screen under the control of the DMDX software (Forster \& Forster, 2003), in a large white sans serif font on a solid black background. The 108 word and nonword stimuli in all presentation conditions were presented mixed within a single run. Participants were instructed to read aloud each item as it appeared on the screen as quickly as possible without making mistakes. Items remained on the screen until the child made a response, at which point the experimenter pressed a button to proceed to the next item. Item order was determined randomly for each participant. Participant responses were recorded via a head-mounted microphone and were timed by a voice key in reference to the onset of the stimulus display with millisecond accuracy.

Analyses. Responses were individually examined using CheckVocal (Protopapas, 2007) to verify (and correct, if necessary) the response time marks and to judge whether each response was pronounced correctly and on which syllable it was stressed. Self-corrections were not considered. If an initial production was complete, then it was taken to be the valid response for that trial, and the latency between the onset of stimulus presentation and the onset of the spoken response was taken to be the corresponding response time (RT). If an initial production was interrupted or dysfluent or otherwise impossible to determine where it was stressed then it was coded as missing. If a response began with an obvious filler (e.g., "eeeh") followed by a complete production, then the filler was ignored and the complete production was taken to be the valid response, adjusting RT accordingly. Each valid response was considered (segmentally) correct when all segments (phonemes) were pronounced, in the correct order. Segmentally incorrect responses typically included minor deviations from the intended pronunciation; no major discrepancies were observed. Stress assignment was judged independently of segmental accuracy, as long as the correct number of syllables were produced, by noting the syllable of the valid response on which stress was clearly pronounced. Stress assignment was then used to calculate effect indices (LexI, PenI, and DiaI) in the same way as in Experiment 1.

\section{Results}

Reading errors and latencies. Table 6 shows the RTs (for segmentally correct responses only) and absolute number of errors for each stimulus type and diacritic presentation condition, separately for each grade. Judging by the mean values, there appears to be a speed-accuracy trade-off, with Grade 3 children responding faster and less accurately than we might expect from their intermediate grade position. To take into account both RT and errors simultaneously, these 


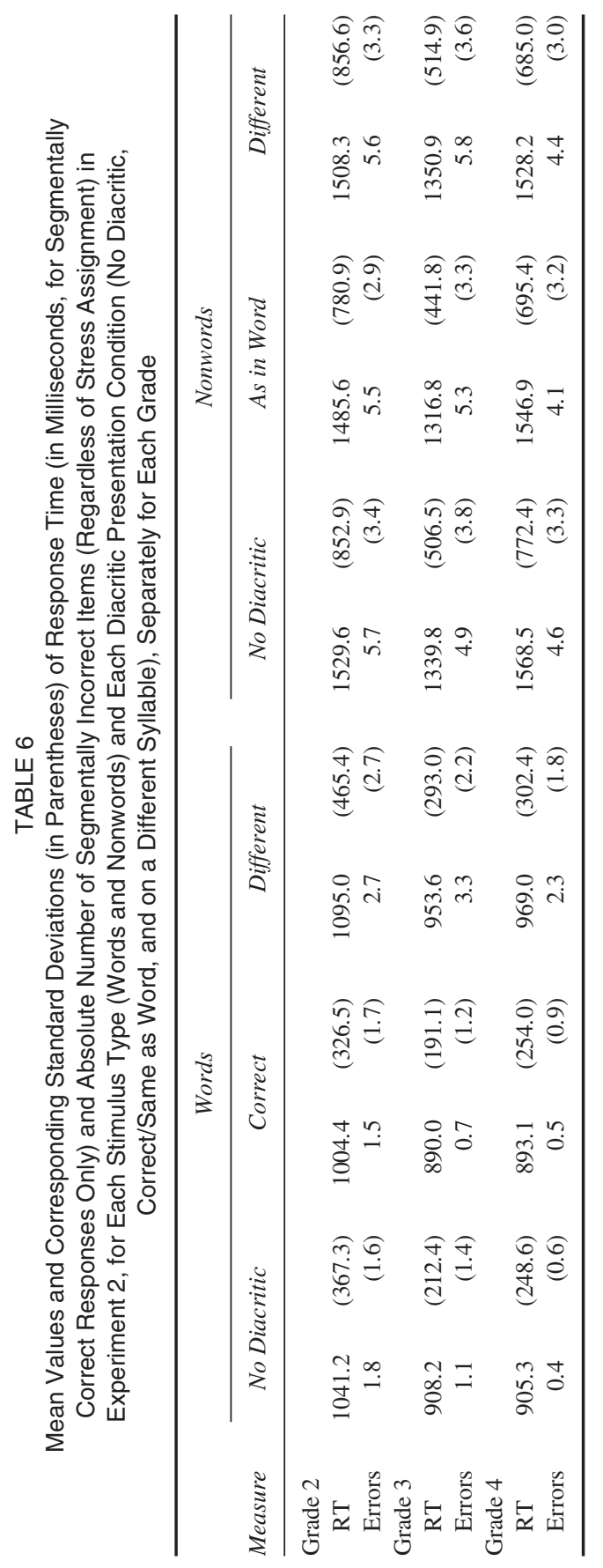


measures were first examined as dependent variables using a multivariate analysis of variance.

For nonwords, there was no significant effect of grade, $F_{1}(4,172)=1.19, p=$ $.319 ; F_{2}(4,50)=10.18, p<.0005$, or diacritic presentation condition, $F_{1}(4,84)<$ $1 ; F_{2}(4,50)=1.09, p=.372$, and no interaction between the two, $F_{1}(8,168)<1$, $F_{2}(8,46)<1$. For words, the main effects of grade, $F_{1}(4,172)=3.32, p=.012$; $F_{2}(4,50)=26.67, p<.0005$, and diacritic condition, $F_{1}(4,84)=14.48, p<$ $.0005 ; F_{2}(4,50)=23.87, p<.0005$, were significant but their interaction was not, $F_{1}(8,168)=1.05, p=.400 ; F_{2}(8,46)=1.78, p=.107$. The diacritic effect was due to a significant difference between the two conditions with a diacritic present, that is, between the diacritic in the same position as the word and the diacritic in a different position: $\mathrm{RT}, F_{1}(1,87)=14.18, p<.0005 ; F_{2}(1,53)=19.97$, $p<.0005$; errors, $F_{1}(1,87)=49.55, p<.0005 ; F_{2}(1,53)=75.19, p<.0005$, with more errors and higher response times in the latter. There were no significant differences between no diacritic and diacritic as in the word: $\mathrm{RT}, F_{1}(1,87)=3.84, p$ $=.053 ; F_{2}(1,53)=2.12, p=.151$; errors, $F_{1}(1,87)=1.82, p=.181 ; F_{2}(1,53)=$ $1.42, p=.239$.

Stress assignment. Stress assignment measures were examined in comparison to those from Experiment 1 (a) to verify that including the words in this experiment did not result in different response patterns to the completely changed nonwords and (b) to test whether patterns of stress assignment on words resemble those for the minimally changed nonwords. Table 7 shows the effect indices for each grade and condition.

In comparison of the two experiments, considering responses to completely changed nonwords only, we found no main effect of experiment on either LexI, $F_{1}(1,174)=5.04, p=.026 ; F_{2}(1,106)<1$, or PenI, $F_{1}(1,174)=10.61, p=.001$; $F_{2}(1,106)=3.16, p=.078$; no interaction of experiment with grade, LexI: $F_{1}(2$, $174)=2.56, p=.081 ; F_{2}(2,212)=1.73, p=.180 ;$ PenI, $F_{1}(2,174)=1.32, p=.270$; $F_{2}(2,212)=3.62, p=.028$; no interaction of experiment with diacritic condition for PenI, $F_{1}(2,348)=3.49, p=.020 ; F_{2}(2,212)<1$; and no three-way interaction between experiment, grade, and diacritic condition, LexI, $F_{1}(4,348)=1.80, p=$ $.128 ; F_{2}(4,424)=4.88, p=.001 ;$ PenI, $F_{1}(4,348)<1 ; F_{2}(4,424)<1$. There was a significant interaction of experiment with diacritic condition for LexI, $F_{1}(2,348)=$ $12.88, p<.0005 ; F_{2}(2,212)=1.95, p<.0005$, arising from a significant effect of experiment on LexI for presentations with the diacritic in the same position as the source word, $F_{1}(1,174)=18.08, p<.0005 ; F_{2}(2,106)=18.29, p<.0005$. Thus the only significant difference between the two experiments, as far as completely changed nonwords are concerned, was a larger influence of the diacritic on stress assignment in Experiment 2, not affecting any comparisons between conditions or the validity of the interpretation. 


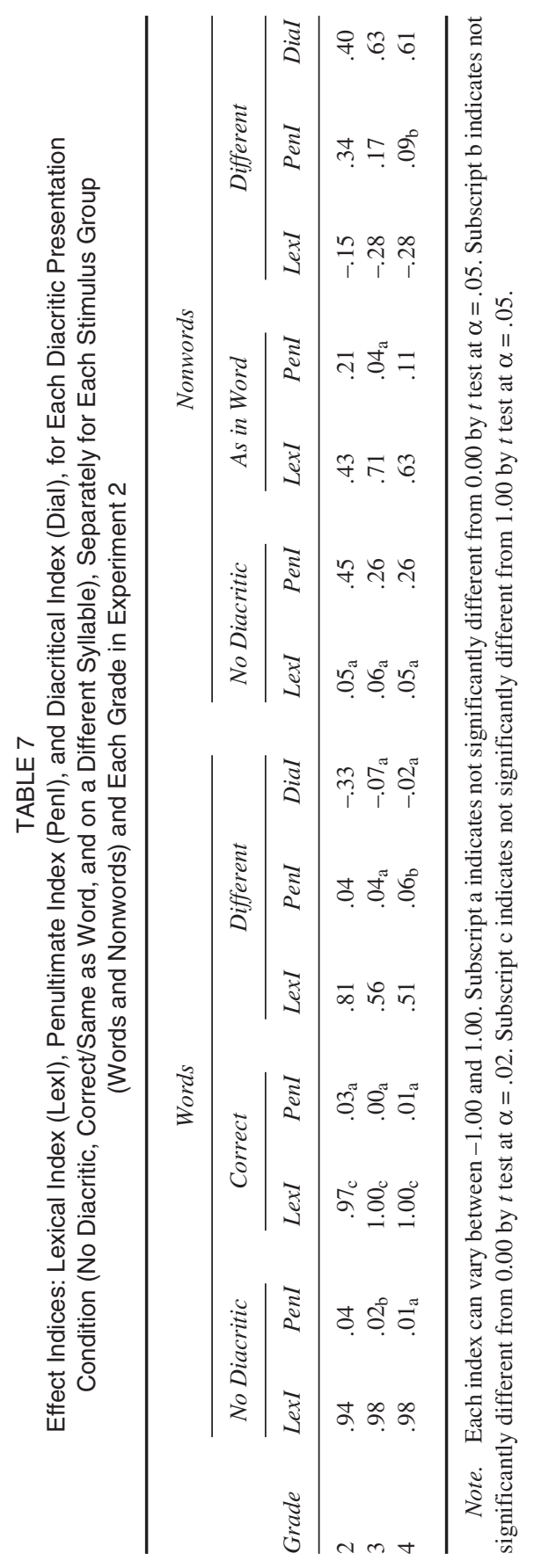


Considering responses to words (Experiment 2) and minimally changed nonwords $($ Experiment 1$)$, there was a main effect of experiment on LexI, $F_{1}(1,174)=$ $155.14, p<.0005 ; F_{2}(1,106)=69.73, p<.0005$; an interaction of experiment with grade, $F_{1}(2,174)=3.06, p=.049 ; F_{2}(2,212)=9.24, p<.0005$; and (marginally) of experiment with diacritic presentation condition, $F_{1}(2,348)=2.55, p=.079 ; F_{2}(2$, $212)=10.36, p<.0005$, but no three-way interaction, $F_{1}(4,348)<1 ; F_{2}(4,424)=$ $1.82, p=.124$. Because all the observed pairwise differences and trends in mean values of LexI were in the same direction in the two Experiments (compare Table 3 to Table 7) it seems likely that the significant interactions arise as a result of ceiling effects in Experiment 2 for LexI, which approached 1.00 for items presented without a diacritic and was statistically indistinguishable from 1.00 for items presented with a diacritic in its correct position. The (marginally) significant interaction of experiment with diacritic condition is apparently due to the larger difference between presentation without a diacritic and presentation with a diacritic on the correct position in Experiment $2\left(\eta_{1}{ }^{2}=.358, \eta_{2}{ }^{2}=.367\right)$ than in Experiment $1\left(\eta_{1}{ }^{2}=\right.$ $.059, \eta_{2}^{2}=.116$ ), both of which were statistically significant.

For PenI there was no significant main effect of experiment, $F_{1}(1,174)=89.50$, $p<.0005 ; F_{2}(1,106)=1.40, p=.240$, and no interaction of experiment with diacritic condition, $F_{1}(2,348)=1.48, p=.230 ; F_{2}(2,212)<1$, or three-way interaction, $F_{1}(4,348)<1 ; F_{2}(4,424)<1$. There was a significant interaction of experiment with grade, $F_{1}(2,174)=4.08, p=.019 ; F_{2}(2,212)=7.40, p=.001$, reflecting the fact that in Experiment 2 there were no significant differences in PenI for words either by grade, $F_{1}(2,87)=1.17, p=.315 ; F_{2}(2,212)<1$, or by diacritic condition, $F_{1}(2,174)=3.90, p=.022 ; F_{2}(2,212)<1$, and no interaction between the two, $F_{1}(4,174)<1 ; F_{2}(4,212)<1$. As PenI was statistically indistinguishable from 0.00 for words in most grades and diacritic conditions in Experiment 2, we may conclude that the default metrical pattern was completely swamped by the specific lexical information.

Developmental trends. Developmental trends were largely consistent with Experiment 1. Dial for nonwords presented with a diacritic in a different position exhibited a significant linear increase with grade $\left(p_{1}=.033, p_{2}<.0005\right)$ and no significant quadratic trend $\left(p_{1}=.139, p_{2}=.001\right)$. PenI for nonwords presented without a diacritic exhibited a significant linear decrease $\left(p_{1}=.009, p_{2}<.0005\right)$ and no quadratic $\left(p_{1}=.106, p_{2}=.041\right)$ trend. LexI for words presented without a diacritic exhibited a significant linear increase $\left(p_{1}=.005, p_{2}=.043\right)$ in the absence of a quadratic trend $\left(p_{1}=.104, p_{2}=.107\right)$. Because of obvious ceiling effects for LexI (mean values of .98, with a maximum of 1.00, at Grades 3 and 4) and associated depressed variance $(S D=.15$ for Grade 2, .05 for Grade 3, and .11 for Grade 4$)$, the difference contrasts were also examined, and found to be significant between Grades 2 and $3\left(p_{1}=.005, p_{2}=.029\right)$ but not between Grades 3 and $4\left(p_{1}=.095, p_{2}\right.$ $=.173)$. 


\section{Discussion}

The results of this experiment are consistent with conclusions from previous studies and strengthen our interpretation of the results of Experiment 1. Stress assignment for words produced the same pattern of results as minimally changed nonwords, only shifted up towards better performance, to the extent possible given the ceiling effect. That is, substituting the source words for the minimally changed nonwords resulted in an increase of the lexical influence, which is expected because of the strong and unimpeded lexical activation, while relations among indices and conditions remained unchanged. This result corroborates our interpretations for the lexical source of stress assignment information in nonwords and indicates that the conclusions can be validly extended to real words.

The lexical source of information appears capable to determine stress assignment almost by itself-but not entirely, because LexI for words presented without a diacritic was statistically less than 1.00. There was thus a (very small) influence of the diacritic in word stress assignment as measured by the effect indices. No such influence was discernible in the RT data, as the responses to words presented with a correct diacritic were not statistically faster than responses to words presented without a diacritic. Taken together, these findings suggest that the diacritic may not be entirely unnecessary for correct stress assignment when reading words but its effects are certainly very small for the ages examined here. It remains to be investigated in future studies whether the diacritic becomes more important when letter sequences are involved that can form different words depending on where

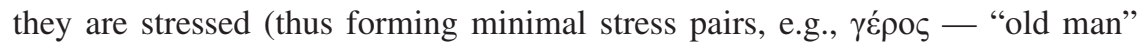
vs. $\gamma \varepsilon \rho o ́ \varsigma \_$"strong"). It is unknown whether Greek readers use the diacritic to disambiguate minimal stress pairs when phrase context provides sufficient constraining information. Further empirical study would be necessary to resolve this issue, because it is not necessarily the case that increased uptake of the diacritic information is indicative of a reliance on the diacritic information.

The greatly protracted period of improvement in processing the diacritic calls for an explanation. As expected, stress assignment performance in word reading was practically perfect in Experiment 2 when the lexical and diacritic sources provided consistent information, that is, when the diacritic was placed at the correct position in the word. More important is the condition in which the two sources were inconsistent, that is, for words presented with a misplaced diacritic (in a "different" position). Here, DiaI failed to differ statistically from 0.00 (except for Grade 2, in which it was significantly less) whereas LexI was significantly greater than $0.00-$ yet significantly decreasing across grades. This means that lexical information almost completely dominated the diacritic in stress assignment even though a slow rise across grades was discernible for the latter. If the diacritic provides so little, either on top or in opposition of the lexical information, it seems reasonable to question the actual opportunity for practice in pro- 
cessing the diacritic children may be getting through their developing reading skills.

That is, if we assume that reading known words occupies the majority of reading time for children in the early school grades, and if the diacritic fails to affect reading known words very substantially or at all, then children may not be accumulating experience, from repeated word reading trials, in processing the diacritic, through which to improve their efficiency of the processing. In other words, if lexical access is sufficiently constrained by the letter sequence so that the diacritic is usually unnecessary, and if decoding the diacritic is difficult and necessarily late-stage, then it follows that learning to process the diacritic will lag behind word recognition because of lack of practice. It would also seem to follow that children do not ever have to learn to decode the diacritic but they do, eventually, incorporate it in their image of the words (the sight-word vocabulary) because it consistently forms part of the visual stimulus and, hence, of the orthographic representation. This interpretation is consistent with the significant effect on RT from an incorrectly placed diacritic (contrasting with no effect of a missing diacritic), because an incorrectly placed diacritic actively mismatches the orthographic representation.

Let us turn to the issue of the default pattern. In agreement with previous studies of stress assignment in reading Greek, we have found a higher proportion of penultimate stress readings than other metrical patterns when specific information sources are unavailable. This tendency was strongest in Grade 2 and decreased significantly in higher grades. We would not expect this decrease to render the effect negligible in higher ages, because similar significant effects have been reported for children in Grades 7 to 9 (Protopapas et al., 2006) and for adults (Protopapas et al., 2007). Therefore, there appears to be a consistent preference of Greek readers to stress the penultimate syllable, and in this sense we call this stress pattern a "default." The origin and nature of this pattern must await further theoretical analysis and empirical investigation in order to be understood. One possibility is that it constitutes some sort of linguistic property of Greek, or of all languages, not depending on knowledge of particular words. For example, Kappa (2002) and MalikoutiDrachman and Drachman (1989) consider the trochaic foot to be unmarked, in the linguistic sense, reflecting a universal, cross-linguistic tendency.

Another possibility is that the "default" pattern arises as a statistical effect of the mental lexicon or because of cumulative activation of particular lexical items, so that it depends crucially on having particular sets of lexical representations and mechanisms of activation. Under such a description, the representations leading to an apparent stress assignment bias would be due to the statistics of language use, perhaps predominantly the history of language input. In support of the role of experience with specific linguistic inputs in determining stress assignment, Tzakosta (2004) found that children acquiring Greek strive to preserve the specific stressed syllable they hear irrespective of the metrical pattern it fits into. She analyzed the 
high variability in the stress patterns observed in very young children's speech as reflecting ambiguous perception of the metrical structure and argued against the idea of a trochaic bias as an unmarked stress pattern.

Several recent findings from reading studies bear on this issue. In Italian, Paizi and Burani (2008) have concluded, on the basis of word naming data, that there is no "dominant" pattern and that stress assignment is based on stress neighborhoods (groups of words sharing stress pattern and word-end segmental representations), replicating and extending earlier findings of Burani and Arduino (2004). In Spanish, Gutiérrez-Palma and Palma-Reyes (2008) argued that, if stress is assigned by default, then words with penultimate stress should be less affected by stress-mark manipulations and should be read more quickly and accurately than words with other stress patterns. However, these predictions were not consistent with their findings, leading them to hypothesize that "sublexical stress assignment follows a more complex algorithm" (p. 655). In English, Arciuli and Cupples (2006) found that typically stressed nouns and verbs were both named and recognized more accurately (but not faster) than atypically stressed ones. However, what is considered "typical" differs between nouns (trochaic) and verbs (iambic). Arciuli and Cupples suggested that "orthographic characteristics of word endings simultaneously cue both lexical stress and grammatical category" (p. 937). Therefore the notion of "regular stress" seems to extend beyond phonology, requiring information about words or word types, and may arise as a distributional property of the lexicon. In a related project, Rastle and Coltheart (2000) included information about word-initial and word-final orthographic patterns in a stress assignment algorithm for a reading model. Although those critical word fragments were predominantly morphemes, they were identified and selected for their "propensity to influence the placement of stress" (p. 348), a propensity that can only be established by reference to the words containing them. Therefore it is possible to analyze this work too as a cumulative (albeit indirect) effect of the lexicon on stress assignment, and not necessarily as a sublexical effect.

Taken together, these findings cast considerable doubt on the notion of a default linguistic property and suggest that the lexicon may be a more fruitful source of stress assignment information, not only by analogy to individual words but also because of cumulative effects of distributed lexical and sublexical representations. The apparent "default" behavior of stressing the penultimate syllable may derive not from an abstract structural characteristic of the language but from the very specific content of the mental lexicon as determined by the statistics of language input and language use.

\section{CONCLUSION AND FUTURE DIRECTIONS}

Orthographic systems employ diacritics, in addition to letters, to convey phonetic, suprasegmental, and other distinctions. Readers learn to recognize and exploit this 
information. We have presented two experiments in which we investigated the development of processing the stress diacritic of the Greek orthography by children in Grades 2 to 4. Consistent with previous studies with older children and adults, we found that the diacritic was minimally attended to at the end of Grade 2, despite relatively fluent reading and 2 years of intensive and explicit reading and writing instruction that includes teaching of the diacritic. Processing of the diacritic increased rapidly at higher grades but remained well below its potential maximum influence on actual reading.

The children tested here were selected to span a highly informative range of reading development, from the beginning of automatic word reading through the establishment of fluent reading patterns. The very early stages of learning about the diacritic remain to be studied, in order to understand the role of stress awareness and early reading skills in the development of stress assignment in reading, in general, and processing the diacritic, in particular. To this end, shorter and easier testing materials that can be handled by Grade 1 children will be needed, along with a more inclusive approach to assessing reading, linguistic, and meta-linguistic skills.

The lexicon has emerged as an important, perhaps dominant, source of stress assignment information in reading. In a somewhat surprising finding, children at the end of Grade 2 already appear to use their word knowledge fluently to guide stress assignment, not only to read words but also for nonwords that resemble words. One possible interpretation of this finding is that stress must be assigned at a late stage of phonological assembly and by that time lexical activation is already available and less costly, in terms of cognitive effort, to access than it would be to compute a metrical pattern by decoding the diacritic, especially for the younger children who are not yet very fluent decoders.

A number of questions are raised by these and related studies, that should be addressed in the future. One set of questions concerns the role of the lexicon, and the activation processes that are involved in stress assignment. In essence, this is a requirement for reading models to incorporate stress assignment by extension to multisyllabic words and explicit representation of stress. To this end, approaches towards computational modeling of stress assignment (e.g., Rastle \& Coltheart, 2000) would have to be extended to include lexical sources of stress assignment information (as in Monaghan et al., 2008; Ševa et al., 2009). Another set of questions concerns the mechanisms involved in processing the diacritic itself, from its visual recognition and association with the underlying letter through the construction of a metrical pattern in conjunction with the simultaneous computation of the segmental or syllabic representation of the word. After a period of focusing primarily on the segmental level, it appears that suprasegmental aspects of reading, including stress assignment, should also capture the attention of reading researchers, towards a more integrated view of expert, fluent reading. 


\section{ACKNOWLEDGMENTS}

We thank Persefoni Bali, Katerina Grimani, and Miltiadis Koutougkos for testing participants and scoring responses, and Cristina Burani, Nicolás GutiérrezPalma, Marina Tzakosta, and Despina Paizi for comments on the manuscript. We are grateful to Lakoniki and Geitonas private schools for their collaboration, and particularly to Yannis Fragkis and Melina Iliopoulou for facilitating the process of testing the children.

\section{REFERENCES}

Arciuli, J., \& Cupples, L. (2006). The processing of lexical stress during visual word recognition: Typicality effects and orthographic correlates. Quarterly Journal of Experimental Psychology, 59, 920-948.

Ashby, J., \& Clifton, C. (2005). The prosodic property of lexical stress affects eye movements during silent reading. Cognition, 96, B89-B100.

Ayçiçeği, A., \& Harris, C. L. (2002). How are letters containing diacritics represented? Repetition blindness for Turkish words. European Journal of Cognitive Psychology, 14, 371-382.

Barca, L., Burani, C., Di Filippo, G., \& Zoccolotti, P. (2006). Italian developmental dyslexic and proficient readers: Where are the differences? Brain and Language, 98, 347-351.

Burani, C., \& Arduino, L. S. (2004). Stress regularity or consistency? Reading aloud Italian polysyllables with different stress patterns. Brain and Language, 90, 318-325.

Colombo, L. (1992). Lexical stress and its interaction with frequency in word pronunciation. Journal of Experimental Psychology: Human Perception and Performance, 18, 987-1003.

Comrie, B. (1996). Languages of eastern and southern Europe. In P. T. Daniels \& W. Bright (Eds.), The world's writing systems (pp. 663-689). New York: Oxford University Press.

Csépe, V. (2006). Literacy acquisition and dyslexia in Hungarian. In R. M. Joshi \& P. G. Aaron (Eds.), Handbook of orthography and literacy (pp. 389-404). Mahwah, NJ: Erlbaum.

Cubelli, R., \& Beschin, N. (2005). The processing of the right-sided accent mark in left neglect dyslexia. Brain and Language, 95, 319-326.

Daniels, P. T., \& Bright, W. (Eds.). (1996). The world's writing systems. New York: Oxford University Press.

Đình-Hoà, N. (1996). Vietnamese. In P. T. Daniels \& W. Bright (Eds.), The world's writing systems (pp. 691-695). New York: Oxford University Press.

Domínguez, A., \& Cuetos, F. (1998). Similitud ortográfica y prosódica en el reconocimiento depalabras. II Congreso de la Sociedad Española de Psicología Experimental (SEPEX), Granada, December 17-18.

Domínguez, A., \& Cuetos, F. (2002). Lexical stress in visual word recognition: Contrastive value in Spanish. Unpublished manuscript.

Forster, K. I., \& Forster, J. C. (2003). DMDX: A Windows display program with millisecond accuracy. Behavior Research Methods, Instruments \& Computers, 35, 116-124.

Gutiérrez Palma, N. (2003). El acento léxico y su función en el reconocimiento de palabras escritas en adultos y en niños [Lexical stress and its role in written word recognition by adults and children]. Unpublished doctoral dissertation, Universidad de Granada, Spain.

Gutiérrez-Palma, N., \& Palma-Reyes, A. (2007). Stress sensitivity and reading performance in Spanish: A study with children. Journal of Research in Reading, 30, 157-168.

Gutiérrez-Palma, N., \& Palma-Reyes, A. (2008). On the use of lexical stress in reading Spanish. Reading and Writing, 21, 645-660.

Kappa, I. (2002). On the acquisition of syllabic structure in Greek. Journal of Greek Linguistics, 3, 1-52. 
Mair, V. H. (1996). Modern Chinese writing. In P. T. Daniels \& W. Bright (Eds.), The world's writing systems (pp. 200-208). New York: Oxford University Press.

Malikouti-Drachman, A. (2002). Greek phonology: A contemporary perspective. Journal of Greek Linguistics, 2, 187-243.

Malikouti-Drachman, A., \& Drachman, G. (1989). Tonismós sta elliniká [Stress in Greek]. Studies in Greek Linguistics, 9, 127-143.

Marcolini, S., Burani, C., \& Colombo, L. (2009). Lexical effects on children's pseudoword reading in a transparent orhography. Reading and Writing, 22, 531-544.

Ministry of Education and Religious Affairs, \& Paedagogical Institute. (1997). I glossa mou, B' dimotikou [My language, Grade 2]. Athens: Organismos ekdoseon didaktikon vivlion.

Monaghan, P., Arciuli, J., \& Seva, N. (2008). Constraints for computational models of reading: Evidence from learning lexical stress. In Proceedings of the 30th annual conference of the cognitive science society (pp. 457-462). Mahwah, NJ: Erlbaum.

Nespor, M., \& Vogel, I. (1986). Prosodic phonology. Dordrecht, the Netherlands: Foris.

Nunes, T., Roazzi, A., \& Buarque, L. L. (2003). Learning to mark stress in written Portuguese. Revue de Linguistique, 22, 99-108.

Pagliuca, G., Arduino, L. S., Barca, L., \& Burani, C. (2008). Fully transparent orthography, yet lexical reading aloud: The lexicality effect in Italian. Language and Cognitive Processes, 23, 422-433.

Paizi, D., \& Burani, C. (2008). Stress assignment in Italian young and adult readers: Friendship rules out dominance. Unpublished manuscript.

Petrounias, E. V. (2002). Neoellinikí grammatikí kai sigkritikí análisi, tómos A: Fonitikí kai eisagogí sti fonología [Modern Greek grammar and comparative analysis, Vol. A: Phonetics and introduction to phonology]. Thessaloniki, Greece: Ziti.

Protopapas, A. (2006). On the use and usefulness of stress diacritics in reading Greek. Reading \& Writing: An Interdisciplinary Journal, 19, 171-198.

Protopapas, A. (2007). CheckVocal: A program to facilitate checking the accuracy and response time of vocal responses from DMDX. Behavior Research Methods, 39, 859-862.

Protopapas, A., Gerakaki, S., \& Alexandri, S. (2006). Lexical and default stress assignment in reading Greek. Journal of Research in Reading, 29, 418-432.

Protopapas, A., Gerakaki, S., \& Alexandri, S. (2007). Sources of information for stress assignment in reading Greek. Applied Psycholinguistics, 28, 695-720.

Protopapas, A., \& Skaloumbakas, C. (2007). Computer-based and traditional screening and diagnosis of reading disabilities in Greek. Journal of Learning Disabilities, 40, 15-36.

Rastle, K., \& Coltheart, M. (2000). Lexical and nonlexical print-to-sound translation of disyllabic words and nonwords. Journal of Memory and Language, 42, 342-364.

Revithiadou, A. (1999). Headmost accent wins: Head dominance and ideal prosodic form in lexical accent systems [LOT Dissertation Series 15 (HIL/Leiden University)]. The Hague, the Netherlands: Holland Academic Graphics. Available at http://roa.rutgers.edu

Ševa, N., Monaghan, P., \& Arciuli, J. (2009). Stressing what is important: Orthographic cues and lexical stress assignment. Journal of Neurolinguistics, 22, 237-249.

Tzakosta, M. (2004). Multiple parallel grammars in the acquisition of stress in Greek L1 [LOT Dissertation Series 93 (HIL/Leiden University)]. The Hague, the Netherlands: Holland Academic Graphics. Available from http://roa.rutgers.edu

Velalidis, A., Voujoukas, A., Kalapanidas, K., Kanakis, N., \& Melas, D. (1994). Glósa A dimotikú: Vivlío daskálu [Language 1st grade: Teacher's book] (I $\Gamma^{\prime}$ ed.). Athens, Greece: Organismos Ekdoseos Didaktikon Vivlion. (Ministry of Education)

Wood, C. (2006). Metrical stress sensitivity in young children and its relationship to phonological awareness and reading. Journal of Research in Reading, 29, 270-287.

Zoccolotti, P., De Luca, M., Di Pace, E., Gasperini, F., Judica, A., \& Spinelli, D. (2005). Word length effect in early reading and in developmental dyslexia. Brain and Language, 93, 369-373. 